\section{Numbers of people}

Population Policy in Developed Countries. Edited by Bernard Berelson. Pp. xiii +793. (A Population Council Book.) (McGraw Hill: New York and London, 1974.) $\$ 17.50$.

THIS is a collection of essays on the present demographic situation and the policies relevant to population growth, composition and distribution in 24 'advanced' countries (including Argentina, Greece and Spain). Bernard Berelson contributes an introduction and a very sensible and comprehensive summary.

It is clear from this collection that Britain, the Netherlands and the United States are the only countries in which there has been any marked concern during the 1960 s with overpopulation, and even in those countries, the concern is muted and becoming more so. In all others, the concern is more with increasing the total population or, as in the cases of Israel and South Africa, with redressing a perceived imbalance between different groups. The reasons for this are various. They include an anxiety about future manpower (even the Netherlands, although worried by high density, encourages immigration), an anxiety about political status (most evident in Argentina and Israel, but by no means absent from many other countries), and a more diffuse anxiety about the dangers of some sort of inertia from stationary or declining numbers. It is interesting that the arguments reviewed for and against rising numbers are all, without exception, inconclusive. The sanest stance is perhaps taken by the Swedes, who seem to be entirely agnostic about the reputed effects of different demographies and concern themselves instead with the maintenance and improvement of the quality of life for those who are already living.

It is also clear from these essays, however, that any country wishing to do anything about its rate of population growth is faced with considerable difficulties. Punitive policies (such as that recently introduced in Singapore) are out of the question for moral and political reasons. And less punitive policies seem to have uncertain or weak effects. There is little moral or political room for manoeuvre over mortality; providing adequate facilities for birth control is no more likely to reduce fertility than is withdrawing them likely to raise it; and although there is considerable political, if not moral, room to alter migration flows, emigration cannot be controlled easily. That leaves immigration, which many societies have used to alleviate their problems. It seems likely, however, that in all but a few cases (one of which, interestingly, seems to be Finland) the supply of potential immigrants is drying up, and where it is not, the potential immigrants are highly undesirable.

This volume therefore gives the impression that national concerns about population are founded upon very uncertain arguments, and that even where action is considered desirable, it is rarely possible to a decisive extent. The interest, perhaps, for scientists is that so few countries pay any attention to the environmental consequences of demographic patterns. In my opinion, that attitude is correct: the connection between population and the environment is at best an indirect one; accordingly, direct measures to protect or improve the environment need be little influenced by population.

\section{G. P. Hawthorn}

\section{Man and fire}

Fire and Ecosystems. (Physiological Ecology: A Series of Monographs, Texts and Treatises.) Edited by T. T. Kozlowski and C. E. Ahlgren. Pp. xii +542. (Academic: New York and London, December 1974.) $\$ 39.50$; £18.95.

To the wildlife conservationist, fire is at the same time a valuable tool and a feared enemy, and it is this love-hate relationship which man has towards fire which forms the underlying theme of this book. It is a collection of regional essays by many eminent ecologists, most of whom are directly concerned with the practical side of forestry, range management or agriculture, and it provides a very extensive review of a subject, which demands the attention of all who are interested in the relationship between man and his environment.

Following a brief introduction there are three chapters, by Viro, Ahlgren and Bendell, of a general nature, which concern the influence of fire on soil, soil organisms, and birds and mammals, respectively. Of these the first, on soil, is very much more limited in its coverage than one might have hoped. Almost all the data quoted concerns podsols in boreal forest areas of Fennoscandia ( $90 \%$ of the literature quoted in the bibliography for this chapter is Scandinavian or Finnish). Although much has been contributed to our knowledge of this subject by scientists from that part of the globe, this presentation represents a very narrow approach to what purports to be a general survey of a very important aspect of the ecology of fire. The chapters on soil microbes and, particularly, on birds and mammals are, however, very full and serve as useful reviews.

There follow, in the main body of the book, sections dealing with the influence of fire on the major biomes of the world, grassland, deciduous and coniferous forests, chaparral and Mediteranean vegetation, and savanna and desert.
Apart from the chapter by Vogl on grasslands, these sections each tend to be devoted to specific geographical regions: for example, the section on forests is divided into four chapters, each dealing with one of the major forested areas of the United States. Although this system of subdivision has undoubtedly made it easier for each of the authors to concentrate on one area of the extensive literature and has also facilitated the task of editing, I feel that some potential has been lost as a result. It would have been useful if some chapters dealing with more general themes could have been incorporated, after the fashion of the first four chapters. But perhaps this attitude is inevitable in west European ecologists as their region is so markedly neglected. Given such a geographically subdivided approach, however, it is sad that space was not found for a chapter dealing with the influence of fire upon heathland and moorland ecology, a subject concerning which there is a wealth of literature. In fact, it is touched upon only briefly, for example, in Bendell's chapter where two pages are given over to the red grouse.

The final chapter, by Kayll, on the use of fire in land management, attempts the kind of synthesis which could have been profitably applied to various other topics in the book. This chapter deserved more space.

Overall, one is left with a book which covers an enormous literature and which is rich in specific examples of fire-adapted species and ecosystems from several parts of the world, but mainly from North America. North American conservationists seeking such specific information will undoubtedly welcome the arrangement of text. Those who seek more general information, however, perhaps relating to fire temperatures and influences upon succession or nutrient cycling processes, will have to collate the numerous, brief references scattered through the text. There are, however, two pervading features for which credit is presumably due to the editors: first, the emphasis upon historic and prehistoric use of fire by man in various biomes and, second, the present day value of fire as a tool in habitat management. These themes are easily traced through most of the chapters, the former reaching a splendid climax in Naveh's biblical and classical account of the history of the use of fire in the Mediterranean region.

The escalating price of this series of monographs on physiological ecology must be remarked upon. This is particularly unfortunate as it is likely to remove them from a rich potential market among nonspecialists, ecologists and conservationists, in whose hands several volumes in the series would have proved particularly valuable.

Peter D. Moore 